\title{
Evaluation of patients' experiences with antidepressants reported by means of a medicine reporting system
}

\author{
E. C. G. van Geffen • S. W. van der Wal • \\ R. van Hulten - M. C. H. de Groot • A. C. G. Egberts • \\ E. R. Heerdink
}

Received: 27 April 2007 / Accepted: 23 August 2007 / Published online: 15 September 2007

(C) Springer-Verlag 2007

\begin{abstract}
Objective To assess experiences related to antidepressant use reported to an internet-based medicine reporting system and to compare the nature of the side effects reported by patients with those reported by health care professionals (HCPs).

Methods All reports submitted from May 2004 to May 2005 to an internet-based medicine reporting system in The Netherlands related to the use of antidepressants were analysed. Spontaneous reports of adverse drug reactions on antidepressants from HCPs received by The Netherlands Pharmacovigilance Centre Lareb from May 2004 to May 2005 were included for comparison.

Results Of the 2232 individuals who submitted a report to the internet-based medicine reporting system, 258 submitted a report on antidepressants. Of these, 92 individuals $(36 \%)$ reported on effectiveness, $40(16 \%)$ of whom reported on ineffectiveness, and $217(84 \%)$ submitted a report on side effects, with $202(78 \%)$ reporting a total of 630 side effects that were experienced as negative. Fourteen individuals $(5 \%)$ reported a practical issue and four $(2 \%)$
\end{abstract}

E. C. G. van Geffen · S. W. van der Wal

Science Shop for Medicines,

Department of Pharmaceutical Sciences, Utrecht University,

P.O. Box 80082, 3508 TB Utrecht, The Netherlands

R. van Hulten · A. C. G. Egberts · E. R. Heerdink $(\bowtie)$

Utrecht Institute for Pharmaceutical Sciences (UIPS),

Department of Pharmacoepidemiology and Pharmacotherapy,

Utrecht University,

P.O. Box 80082, 3508 TB Utrecht, The Netherlands

e-mail: e.r.heerdink@uu.nl

M. C. H. de Groot

Netherlands Pharmacovigilance Centre Lareb,

Goudsbloemvallei 7,

$5237 \mathrm{MH}$ 's Hertogenbosch, The Netherlands reported a reimbursement issue. Of all 630 side effects reported, $48 \%$ resulted in the patient discontinuing the antidepressant therapy; of these $29 \%$ did not inform their HCP. Of all the side effects reported, $52 \%$ were perceived as "very negative". In comparison to the side effects reported by HCPs, patients more often reported apathy, excessive sweating, ineffectiveness, somnolence, insomnia, sexual problems and weight increase.

Conclusion Patients report the ineffectiveness and side effects of antidepressant therapy as negative and leading to discontinuation of the therapy. Patients and HCPs differ in the nature of the reported side effects. Patient experiences should be included in the evaluation of antidepressant treatment in clinical practice.

Keywords Adverse events · Antidepressants .

Discontinuation $\cdot$ Patient reporting

\section{Introduction}

Non-adherence to prescribed medication regimens is a persistent problem in the treatment of depression with antidepressants. Premature discontinuation, dosing lapses and partial non-adherence often occur [1-3]. The illness itself as well as physician-, patient- and treatment-related factors have been suggested to contribute to antidepressant non-adherence, but the ability of health care professionals (HCP) to predict who discontinues medication remains poor [4-6]. Earlier studies provide scant information on how patients in clinical practice perceive their treatment with antidepressants, thus insight and an understanding of the patients' perspectives on non-adherence and discontinuation are limited. Side effects and ineffectiveness are the 
major reasons cited for the discontinuation of antidepressant therapy [7, 8]. However, the information available on side effects is mostly based on controlled clinical trials, which standardly do not evaluate how bothersome side effects are to the individual patient. Moreover, both the side effects and the effectiveness of the antidepressant therapy observed in clinical trials may not reflect the experiences of the patients in real world settings. Many interventions have been developed to improve adherence to antidepressants, but to date these have failed to demonstrate a clear benefit $[9,10]$. Treatment non-adherence remains one of the least understood health-related behaviours. Information received directly from the patient may improve our understanding of the relative importance of antidepressant treatment issues and, consequently, help to explain patients' behaviour towards antidepressant use.

Reporting systems have shown to be a useful tool in collecting experiences and identifying issues related to the daily use of medicines [11]. In 2004, an internet-based medicine reporting system was established in The Netherlands where users of medicines are able to report all types of experiences with medicines - side effects as well as experiences with effectiveness and practical and reimbursement issues. We extracted data from this medicine reporting system in order to (1) assess the type of experiences related to antidepressant use reported by patients, (2) assess the relevance of these experiences and (3) compare the nature of the suspected side effects reported by patients with those reported by HCPs.

\section{Methods}

\section{Setting}

Reports were obtained from an internet-based medicine reporting system launched on 11 May 2004 in The Netherlands. This reporting system was initiated by DGV, The Dutch Institute for the Proper Use of Medicine, the Science Shop for Medicines and patient and consumer organisations. Individuals are able to report their experiences with medicines anonymously by completing a report form downloaded by accessing a website (http://www. meldpuntmedicijnen.nl). Users of the medicine themselves as well as their relatives, acquaintances or (professional) carers, can report an experience. All reports submitted between 11 May 2004 and 13 May 2005 related to the use of antidepressants were reviewed for the clarity and completeness of the description of the experience and checked for multiple reports from the same IP-address. One duplicate report had to be excluded. All other reports were included in the study. The data were stored in an Access database.
Report form

The report form contained items which requested information on age, gender, type of medicine used, nature of the experience, a description of the experience and the relevance of the experience. Individuals filling in the report had to indicate whether the experience was related to either effectiveness, a side effect, a practical issue (e.g. difficulties with swallowing tablets) or a reimbursement issue. More than one experience related to the same drug could be submitted. Experiences related to effectiveness had to be further specified by the individual by selecting one of the following categories: ineffectiveness, a positive effect or a different type of effect (e.g. drug interactions). Experiences related to side effects had to be further specified by selecting one of the following categories: negative side effects, positive side effects (e.g. less side effects as compared with previous medication) or the absence of side effects. Relevance of the experience was assessed by asking the individual filling in the report to indicate both the impact of the experience on a 5-point scale (ranging from very negative to very positive) and whether the experience caused a change in antidepressant use. To specify the change in antidepressant use, those reporting had to select one of the following categories: discontinuation, switching to other treatment, adjustment of dosage or administration, any other action taken or no action taken. In the case of discontinuation of the antidepressant, the report also asked whether the HCP has been informed.

Side effects

All reported side effects (including experiences on ineffectiveness) were coded by one of the authors ( $\mathrm{SvdW}$ ) and checked by a second author (EvG), using preferred terms of the World Health Organisation Adverse Reaction Terminology (WHO-ART) [12]. Preferred terms were combined into groups of similar side effects. Spontaneous reports of adverse drug reactions on antidepressants received from HCPs from May 2004 to May 2005 were included for comparison. These reports were received by The Netherlands Pharmacovigilance Centre Lareb either on paper forms or electronically via http://www.lareb.nl. Coding and assessment were carried out by qualified assessors from Lareb [13].

\section{Data analysis}

The relevance of the side effects was assessed by comparing the impact of the (grouped) side effects as a proportion of the side effects that were perceived as "very negative". Relevance was also assessed by comparing the proportion of the side effects that caused discontinuation of initial antidepressant use, including the categories "discon- 
tinuation" and "switching to other treatment". The impact and discontinuation proportions of the different groups of side effects were compared using the chi-square test.

For the comparison between patients and HCPs, the groups of side effects were compared and expressed as an Odds Ratio (OR) and 95\% confidence interval (CI). The 15 most frequently reported (groups of) side effects by patients as well as the 15 most frequently reported (groups of) side effects by HCPs were included in the analysis.

\section{Results}

\section{Characteristics}

In total 2232 individuals submitted a report to the medicine reporting system during the study period, of whom 258 (12\%) submitted a report on antidepressants. Of these 258 individuals, 248 (96\%) reported for themselves and ten reported for a relative or acquaintance.

The mean $( \pm \mathrm{SD})$ age of the of the antidepressant users was $42.8( \pm 13.5)$ years and $72 \%$ were female. The majority of those reporting on antidepressants $(63 \%)$ were reporting on a serotonin-reuptake inhibitor (SSRI); $12 \%$ were reporting on a tricyclic antidepressant (TCA) and $25 \%$ on another type of antidepressant. The antidepressants most frequently reported on were paroxetine ( $35 \%$ of total), venlafaxine $(15 \%)$, citalopram (10\%) and mirtazapine (8\%). The use of a benzodiazepine as a concomitant drug was reported by $19 \%$ of those reporting on antidepressant use.

\section{Nature of experiences}

The 258 individuals reporting on antidepressant use described 327 experiences. Table 1 shows the nature of the experiences described. Ninety-two individuals (36\%) described an experience with effectiveness, of whom 40 (16\%) described an experience with ineffectiveness. Four individuals claimed generic substitution as the reason for ineffectiveness, and 45 (17\%) reported a positive experience with the effectiveness of an antidepressant. "Other type of effects" in terms of effectiveness that were submitted by seven (3\%) individuals included experiences on suspected drug interactions.

In total, 217 of the 258 individuals (84\%) reporting on antidepressant use submitted a report on side effects. Of these, $202(78 \%)$ described a total of 630 side effects that were experienced as negative. The number of reported side effects ranged from 1 to 11 per reporter experiencing a negative side effect. Twelve individuals $(5 \%)$ reported that they had not experienced any side effect at all, and three (1\%) submitted a positive experience with side effects, reporting that their current antidepressant therapy caused fewer side effects than their previous medication.
Table 1 Nature of the reported experiences related to antidepressant use reported to a medicine reporting system (http://www.meldpuntmedicijnen.nl) ${ }^{\mathrm{a}}$

\begin{tabular}{|c|c|c|c|}
\hline Issue & $\begin{array}{l}\text { Proportion of total } \\
\text { number of } \\
\text { individuals ( } n= \\
258 \text { ) reporting on } \\
\text { antidepressant use }\end{array}$ & $\begin{array}{l}\text { Nature of } \\
\text { issue }\end{array}$ & $\begin{array}{l}\text { Proportion } \\
\text { individuals } \\
\text { reporting on a } \\
\text { specific issue }\end{array}$ \\
\hline \multirow[t]{3}{*}{ Effectiveness } & $36 \%(n=92)$ & Ineffectiveness & $16 \%(n=40)$ \\
\hline & & Positive effect & $17 \%(n=45)$ \\
\hline & & Other & $3 \%(n=7)$ \\
\hline \multirow[t]{3}{*}{ Side effects } & $84 \%(n=217)$ & $\begin{array}{l}\text { Negative side } \\
\text { effect }\end{array}$ & $78 \%(n=202)$ \\
\hline & & $\begin{array}{l}\text { Positive side } \\
\text { effect }\end{array}$ & $1 \%(n=3)$ \\
\hline & & $\begin{array}{l}\text { Absence of } \\
\text { side effect }\end{array}$ & $5 \%(n=12)$ \\
\hline Practical issues & $5 \%(n=14)$ & & \\
\hline $\begin{array}{l}\text { Reimbursement } \\
\text { and } \\
\text { availability } \\
\text { issues }\end{array}$ & $2 \%(n=4)$ & & \\
\hline
\end{tabular}

${ }^{a}$ A total of 258 reporters submitted 327 experiences. The reported experiences are expressed as a percentage of the total number of individuals submitting reports

Fourteen individuals $(5 \%)$ reported a practical issue (such as problems with swallowing tablets or bad taste), and four $(2 \%)$ reported a reimbursement or availability issue (receiving treatment for a relative short duration).

Box 1 shows a number of the reported experiences.

\section{Relevance of side effects}

Table 2 shows the relevance, impact and discontinuation rates of the most frequently reported side effects. Of all side effects, $48 \%$ resulted in discontinuation of the initial antidepressant therapy. The proportion of side effects that caused discontinuation of the initial antidepressant did not differ significantly between the different side effects. Of those individuals who simultaneously reported an experience on side effects and one on ineffectiveness, 59\% (17/29) reported that their experience resulted in discontinuation of the initial antidepressant therapy. Of all individuals who reported discontinuation of therapy, $29 \%$ did not inform their HCP.

Of all side effects, $52 \%$ were perceived as "very negative". The impact of the side effects differed almost significantly between the groups of side effects $(p=0.052)$, with headache, dizziness and fainting perceived as most negative.

Side effects compared between patients and HCPs

Table 3 presents those side effects most frequently reported by patients and HCPs. Patients and HCPs differed in the 
Table 2 Relevance of the most frequently reported side effects related to antidepressant use

\begin{tabular}{llll}
\hline Side effect & $\begin{array}{l}\text { Number of } \\
\text { reported } \\
\text { experiences } \\
(n)\end{array}$ & $\begin{array}{l}\text { Impact (\% } \\
\text { perceived } \\
\text { as "very } \\
\text { negative") }\end{array}$ & $\begin{array}{l}\text { Discontinuation of } \\
\text { antidepressant } \\
\text { use (\%) }\end{array}$ \\
\hline Sleep disorder & 68 & 47 & 50 \\
Somnolence, & 39 & 51 & 59 \\
$\quad$ drowsiness, fatigue & & & \\
Insomnia, & 29 & 41 & 38 \\
$\quad$ sleeplessness & & & \\
Weight increase & 48 & 46 & 56 \\
Sexual problems & 43 & 44 & 33 \\
Discontinuation & 40 & 43 & 50 \\
symptoms & & & \\
Ineffectiveness & 40 & 35 & 53 \\
Apathy & 28 & 46 & 54 \\
Excessive sweating & 23 & 43 & 39 \\
Nausea, gagging & 23 & 39 & 30 \\
Dizziness, fainting & 23 & 65 & 35 \\
Headache & 22 & 68 & 50 \\
Dry mouth & 18 & 50 & 61 \\
Suicidal attempt, & 9 & 78 & 78 \\
thought or tendency & & & \\
a & & & \\
\hline
\end{tabular}
${ }^{\text {a }}$ Suicidal attempts, thoughts or tendency is also included, although the
number of reported experiences was less than 15 .

nature of reported side effects. Compared with HCPs, patients reported significantly more events such as apathy, excessive sweating, ineffectiveness, discontinuation symptoms, somnolence, insomnia, sexual problems and weight increase. HCPs reported significantly more rash, pruritis, laboratory abnormalities, muscle and joint complaints, congenital disorders, eye disorders, extrapyramidal disorders and menstrual disorders than patients.

\section{Discussion}

Both side effects and a lack of effectiveness appear to be important treatment issues for patients who reported on antidepressants in our study. Most of the individuals reporting on antidepressant use described one or more side effects, of which the most frequent were weight increase, sexual problems, somnolence, insomnia and apathy. Ineffectiveness was also reported by a considerable number of individuals. Ineffectiveness is not often reported in literature as an adverse effect of treatment [14]. However, our study reveals that it is a relevant issue for patients during antidepressant therapy. The fact that side effects tend to occur before the therapeutic effect of the antidepressant is perceived may play an important part in explaining early discontinuation of the therapy. Ineffectiveness should therefore receive attention from HCPs in order to prevent early discontinuation of antidepressants.
One of the unique features of this medicine reporting system is the possibility to gather information on the relevance of the experiences - that is the impact of the experience and the change in initial treatment. Overall, half of the experiences were perceived as very negative. Experience of one or more bothersome side effects means an individual is threefold more likely to stop taking antidepressants [7]. Our results show that one half of the side effects resulted in discontinuation of the initial antidepressant therapy. Moreover, of all those individuals who reported discontinuation of therapy, $29 \%$ did not even inform their HCP. This supports the concept that this medicine reporting system provides data of which HCPs are often not aware, but which are of crucial importance to any understanding of patients' behaviour related to the use of antidepressants.

Patients and HCPs differed in the nature of the side effects reported. Patients were found to report more frequently those events which may be less tangible and visible to HCPs, such as sleeping problems and apathy. In addition, HCPs may consider symptoms reported by patients with psychiatric disorders as a symptom of the disease rather than as one related to the medication. Other notable differences between patients and HCPs in terms of the frequency of reported side effects were those of weight increase, sexual problems, discontinuation symptoms and excessive sweating. The differences in the nature of the reported side effects show that patients and HCPs differ in which type of side effects can be considered to be bothersome and/or relevant to report. The burden of side effects is clearly underestimated by HCPs [15]. Although HCPs are knowledgeable on the side effects related to SSRI use, they underestimate the frequency of these side effects and how bothersome they are to patients [16]. In addition, HCPs may be reticent in reporting a side effect to a reporting system. More than patients, HCPs evaluate the side effect reported by the patient according to perceived relevance and causality related to the medication. Side effects which are considered by the HCP as well-known or not related to the medication consequently get lost to the health care system [17].

Patient reporting is not yet widely accepted, and the number of systems collecting experiences from patients is still limited. In the UK, the Prescription-Event Monitoring (PEM) system seeks to identify adverse events recorded following the use of newly marketed drugs selected for monitoring on the first $20,000-50,000$ patients given the new drug [18]. Since the middle of 2003, the Danish Medicines Agency and the Netherlands Pharmacovigilance Centre Lareb also accept reports on adverse drug reactions from patients [19]. In Sweden, the KILEN Consumer Institute for Medicines and Health started a consumer database in 1997 that collects experiences related mainly to 
Table 3 Reported side effects on antidepressants by patients compared with reported side effects on antidepressants by health care professionals (HCPs)

\begin{tabular}{|c|c|c|c|c|c|}
\hline Side effect & $\begin{array}{l}\text { Number of reported } \\
\text { side effects by } \\
\text { patients }\end{array}$ & $\begin{array}{l}\text { Percentage of total } \\
\text { number of side } \\
\text { effects } \\
(n=670)\end{array}$ & $\begin{array}{l}\text { Number of } \\
\text { reported } \\
\text { side effects } \\
\text { by HCPs }\end{array}$ & $\begin{array}{l}\text { Percentage of total } \\
\text { number } \\
\text { of side effects } \\
(n=471)\end{array}$ & $\begin{array}{l}\text { Odds ratio } \\
(95 \% \mathrm{CI})^{\mathrm{a}}\end{array}$ \\
\hline \multicolumn{6}{|c|}{ Top 15 most frequently reported side effects by patients } \\
\hline Weight increase & 48 & 7.2 & 6 & 1.3 & $5.98(2.54-14.09)$ \\
\hline Sexual problems & 43 & 6.4 & 6 & 1.3 & $5.31(2.24-12.59)$ \\
\hline Discontinuation symptoms & 40 & 6.0 & 3 & 0.6 & $14.14(4.35-45.93)$ \\
\hline Ineffectiveness & 40 & 6.0 & 3 & 0.6 & $14.14(4.35-45.93)$ \\
\hline Somnolence, drowsiness, fatigue & 39 & 5.8 & 8 & 1.7 & $3.58(1.66-7.73)$ \\
\hline Insomnia, sleeplessness & 29 & 4.3 & 4 & 0.8 & $5.28(1.84-15.13)$ \\
\hline Apathy & 28 & 4.2 & 0 & 0 & - \\
\hline Excessive sweating & 23 & 3.4 & 0 & 0 & - \\
\hline Nausea, gagging ${ }^{\mathrm{b}}$ & 23 & 3.4 & 8 & 1.7 & $2.05(0.91-4.64)$ \\
\hline Dizziness, fainting ${ }^{\mathrm{b}}$ & 23 & 3.4 & 8 & 1.7 & $2.05(0.91-4.64)$ \\
\hline Headache $^{\mathrm{b}}$ & 22 & 3.3 & 11 & 2.3 & $1.42(0.68-2.96)$ \\
\hline Dry mouth & 18 & 2.7 & 3 & 0.6 & $4.31(1.26-14.71)$ \\
\hline Abdominal pain & 14 & 2.1 & 3 & 0.6 & $3.33(0.95-11.65)$ \\
\hline Anxiety & 13 & 1.9 & 2 & 0.4 & $4.64(1.04-20.66)$ \\
\hline Depressed mood & 11 & 1.6 & 3 & 0.6 & $2.60(0.72-9.39)$ \\
\hline \multicolumn{6}{|c|}{ Top 15 most frequently reported side effects by HCPs } \\
\hline Rash, urticaria and pruritis & 3 & 0.4 & 23 & 4.9 & $0.09(0.03-0.29)$ \\
\hline Laboratory abnormalities & 0 & 0 & 22 & 4.7 & - \\
\hline Muscle and joint complaints & 3 & 0.4 & 20 & 4.2 & $0.10(0.03-0.34)$ \\
\hline Congenital disorders & 0 & 0 & 15 & 3.2 & - \\
\hline Eye and vision disorders & 6 & 0.9 & 15 & 3.2 & $0.27(0.11-0.71)$ \\
\hline Paraesthesia & 8 & 1.2 & 12 & 2.5 & $0.46(0.19-1.14)$ \\
\hline Headache $^{\mathrm{b}}$ & 22 & 3.3 & 11 & 2.3 & $1.42(0.68-2.96)$ \\
\hline Extrapyramidal disorders, Parkinsonism & 1 & 0.1 & 10 & 2.1 & $0.07(0.01-0.54)$ \\
\hline Menstrual disorders, vaginal bleedings & 3 & 0.4 & 10 & 2.1 & $0.21(0.06-0.76)$ \\
\hline Heart rhythm problems & 7 & 1.0 & 10 & 2.1 & $0.49(0.18-1.29)$ \\
\hline Convulsions, epilepsy & 0 & 0 & 9 & 1.9 & - \\
\hline Drug substitution problems & 7 & 1.0 & 8 & 1.7 & $0.61(0.22-1.70)$ \\
\hline Serotonin syndrome & 0 & 0 & 8 & 1.7 & - \\
\hline Nausea, gagging ${ }^{\mathrm{b}}$ & 23 & 3.4 & 8 & 1.7 & $2.06(0.91-4.64)$ \\
\hline Dizziness, fainting ${ }^{\mathrm{b}}$ & 23 & 3.4 & 8 & 1.7 & $2.06(0.91-4.64)$ \\
\hline
\end{tabular}

95\% CI, 95\% confidence interval

${ }^{a} \mathrm{OR}>1$ : Patients were more likely to report the side effect than the HCPs; OR $<1$ : HCPs were more likely to report the side effect than the patients

b Side effects that appear in both the patients' and HCPs' list

dependence and side effects of benzodiazepine and antidepressant use [19]. However, these systems focus only on adverse events, while other aspects of medicine use, including experiences on ineffectiveness, practical and reimbursement issues, have also been shown to be relevant to patients.

A limitation of this internet-based reporting system is that the reporters are anonymous and, therefore, further contact and feedback are not possible. Consequently, a thorough assessment of causality between the side effect and the antidepressant was not always possible. The Netherlands Pharmacovigilance Centre Lareb, on the other hand, whose primary aim is the early detection of new adverse drug reactions, has the facilities to request further medical information by contacting the patient and/or his/her
HCP [20]. However, we believe this does not detract from our conclusion. The individuals reporting through the internet-based reporting system proved to be capable of providing clear descriptions of their experiences and of balancing the benefits and burden of treatment. The patient experiences provide important information on how patients in clinical practice perceive treatment with antidepressants. Such patients experience sleep disorders, weight increase, sexual problems, apathy and ineffectiveness as events which have a negative impact and which frequently lead to discontinuation of the antidepressant therapy. Because adherence decisions are mostly a rational balance of perceived benefits versus burden [21], an assessment of patient experiences may improve the understanding of patients' behaviour towards antidepressant use. This information can 
be used in the development of more targeted adherenceenhancing strategies that may lead to optimisation of antidepressant treatment from the perspective of both HCPs and patients.

\section{Appendix}

Box 1: Examples of experiences reported to the patient reporting system

\section{Effectiveness and side effects}

The medicine works well; its advantage is that it doesn't feel like a 'blanket' is draped over you as with medicines such as oxazepam. By the way, the less expensive substitute paroxetine didn't work for me. The use of Seroxat has the major drawback that it is physically addictive! After taking it for a year and a half, tapering off was next to impossible and certainly not in the way it is stated in the information leaflet. During use I experienced the following side-effects: itchiness, mucous buildup in the throat, incomplete voiding, sensitivity to light, blurred vision, increased heart-rate, concentration disturbances, sweating, nausea, constipation.

Ineffectiveness and side effects

The medicine doesn't work and the side effects are worse than the ailment. Furthermore some side effects aren't even mentioned in the information leaflet, such as permanent damage to teeth. Side effects are: being unable to concentrate, a blurring of emotions, cavities - dentists can tell by the teeth if a person is taking SSRIs, tremors (it's as if I'm an alcoholic), insomnia and lack of deep-sleep, constant headaches (in the back of the head), a continuous nagging pain in all limbs. Like having a hangover - feeling apathetic.

Side effects

I tapered off the medicine in one month and had many side effects: rapid mood changes, 'flashes' in the head, sharpening of senses - seeing and hearing, anxiety, dizziness, nausea, headaches, diarrhoea, panic attacks, heart palpitations, fainting. I did not experience these side effects until I stopped using the medicine.

Practical issues

The tablet doesn't have a smooth layer, causing it to get stuck in the esophagus quite frequently. This, in turn, leads to a foul taste in the mouth, an unpleasant sensation, retching, sometimes only resolved by vomiting. This is really disturbing to me and I don't understand why the manufacturer doesn't make the effort to add a smooth layer around the tablets.

Reimbursement and availability issues

It's a real burden to me that this medicine, which I have to take permanently, is always prescribed for just thirty days (without a refill prescription). I always have to get a new prescription, which is completely unnecessary, especially if you take into account the costs of prescribing. 


\section{References}

1. Lin EHB, Von Korff M, Katon W, Bush T, Simon ES, Walker E, Robinson P (1995) The role of the primary care physician in patients' adherence to antidepressant therapy. Med Care 33:67-74

2. Meijer WEE, Bouvy ML, Heerdink ER, Urquhart J, Leufkens HMG (2001) Spontaneous lapses in dosing during chronic treatment with selective serotonin reuptake inhibitors. $\mathrm{Br} \mathrm{J}$ Psychiatry 179:519-522

3. Bambauer KZ, Adams AS, Zhang F, Minkoff N, Grande A, Weisblatt R, Soumerai SB, Ross-Degnan D (2006) Physicians alerts to increase antidepressant adherence. Arch Intern Med 166:498-504

4. Cohen N, Parikh SV, Kennedy SH (2000) Medication compliance in mood disorders: relevance of the Healt Belief Model and other determinants. Prim Care Psychiatry 6:101-110

5. Lingam R, Scott J (2002) Treatment non-adherence in affective disorders. Acta Psychiatr Scand 105:164-172

6. van Dijk L, Heerdink E, Somai D, van Dulmen S, Sluijs E, de Ridder D, Griens AMGF, Bensing JM (2007) Patient risk profiles and practice variation in non adherence to antidepressants, antihypertensives and oral hypoglycemics. BMC Health Serv Res 7:51-61

7. Bull SA, Hunkeler EM, Lee JY, Rowland CR, Williamson TE, Schwab JR, Hurt SW (2002) Discontinuation or switching selective serotonin-reuptake inhibitors. Ann Pharmacother 36:578-584

8. Demyttenaere K, Enzlin P, Dewé W, Boulanger B, Bie JD, Troyer WD, Mesters P (2001) Compliance with antidepressants in a primary care setting, 1: beyond lack of efficacy and adverse events. J Clin Psychiatry 62[Suppl 22]:30-33

9. Vergouwen ACM, Bakker A, Katon WJ, Verheij TJ, Koerselman F (2003) Improving adherence to antidepressants: a systematic review of interventions. J Clin Psychiatry 64:1415-1420

10. Pampallona S, Bollini B, Tibaldi G, Kupelnick B, Munizza C (2002) Patient adherence in the treatment of depression. Br J Psychiatry 180:104-109
11. Egberts ACG, Smulders M, De Koning FHP, Meyboom RHB, Leufkens HMG (1996) Can adverse drug reactions be detected earlier? A comparison of reports by patients and professionals. $\mathrm{Br}$ Med J 313:530-531

12. Anonymous (2001) International monitoring of adverse reactions to drugs. Adverse reaction terminology. WHO Collaborating Centre for International Drug Monitoring, Uppsala

13. Van Puijenbroek E, Grootheest VAC, Diemont WL, Leufkens HGM, Egberts ACG (2002) Determinants of signal selection in a spontaneous reporting system for adverse drug reactions. Br J Clin Pharmacol 52:579-586

14. Meyboom RHB, Lindquist M, Flygare A-K, Biriell C, Edwards IR (2000). The value of reporting therapeutic ineffectiveness as an adverse drug reaction. Drug Safety 23:95-99

15. Mitchell AJ (2006) High medication discontinuation rates in psychiatry. How often is it understandable? J Clin Psychopharmacol 26:109-112

16. Hu XH, Bull SA, Hunkeler EM, Ming EE, Lee JY, Fireman B, Markson LE (2004) Incidence and duration of side effects and those rated as bothersome with selective serotonin reuptake inhibitor treatment for depression: patient reports versus physician estimate. J Clin Psychiatry 65:959-965

17. Eland IA, Belton KJ, Grootheest vAC, Meiners AP, Rawlins MD, Stricker BHC (1999) Attitudinal survey of voluntary reporting of adverse drug reactions. Br J Clin Pharmacol 48:623-627

18. Inman W, Rawson N, Wilton L, Pearce G, Speirs C (1988) Postmarketing surveillance of enalapril I: results of prescription-event monitoring. Br Med J 297:826-829

19. Blenkinsopp A, Wilkie P, Wang M, Routledge P (2006) Patient reporting of suspected adverse drug reactions: a review of published experience. Br J Clin Pharmacol 63:148-156

20. Van Grootheest AC, Passier JL, Van Puijenbroek EP (2005) Direct reporting of side effects by the patient: favourable experience in the first year. Ned Tijdschr Geneeskunde 149:529-533

21. Aikens JE, Nease DE, Nau DP, Klinkman MS, Schwenk TL (2005) Adherence to maintenance-phase antidepressant medication as a function of patient beliefs about medication. Ann Fam Med 3:23-30 